\title{
BMJ Open At the grassroots of home and community-based aged care: strategies for successful consumer engagement
}

\author{
Lindsey Brett, ${ }^{1}$ Joyce Siette, ${ }^{1}$ Amy Nguyen, ${ }^{1}$ Mikaela Jorgensen, ${ }^{1}$ Melissa Miao, ${ }^{1}$ \\ Johanna Westbrook, ${ }^{1}$ Winifred Lee, ${ }^{2}$ Edwina Gow, ${ }^{2}$ Fleur Hourihan, ${ }^{3}$ \\ Andrew Georgiou ${ }^{1}$
}

To cite: Brett L, Siette J, Nguyen A, et al. At the grassroots of home and community-based aged care: strategies for successful consumer engagement. BMJ Open 2019;9:e028754. doi:10.1136/ bmjopen-2018-028754

- Prepublication history for this paper is available online. To view these files, please visit the journal online (http://dx.doi org/10.1136/bmjopen-2018028754).

Received 21 December 2018 Revised 17 October 2019 Accepted 24 October 2019

Check for updates

(c) Author(s) (or their employer(s)) 2019. Re-use permitted under CC BY-NC. No commercial re-use. See rights and permissions. Published by BMJ.

${ }^{1}$ Australian Institute of Health Innovation, Macquarie University Faculty of Medicine and Health Sciences, Sydney, New South Wales, Australia

${ }^{2}$ Uniting, Chatswood, New South Wales, Australia

${ }^{3}$ Centre for Research and Social Policy, Uniting, Sydney, New

South Wales, Australia

Correspondence to

Dr Lindsey Brett;

lindsey.brett@mq.edu.au

\section{ABSTRACT}

Objectives (1) To describe the processes used to plan and conduct a stakeholder forum in aged care as a means of informing future uptake of consumer participatory research. (2) To discuss how capturing and drawing on stakeholders' experiences of aged care can generate new research ideas and inform the delivery of more personcentred aged care services.

Key principles of consumer engagement $A$ stakeholder forum was conducted as part of Ageing Well, a 2year project evaluating the value and impact of social participation and quality of life tools as part of routine community aged care assessments at a large Australian provider. The forum was codesigned with community aged care clients and care coordinators and aimed to coproduce implementation strategies with a targeted representation of stakeholders. The stakeholder forum was developed using five key principles of consumer engagement activities: purposeful, inclusive, timely, transparent and respectful. The forum fostered an environment of mutual respect and collective inquiry to encourage contributions from all participants. This article outlines practical guidance on using a consumer engagement framework and the lessons learnt.

Discussion The stakeholder forum facilitated an understanding of consumers' needs and existing gaps in aged care services and the circumstances that can enable or hinder the delivery and implementation of these services. This collective information can guide future research and policy at institutional, regional and national committees that relate to aged care.

Trial registration number ACTRN12617001212347

\section{BACKGROUND}

Consumer engagement in healthcare research

A healthcare consumer is defined as a person who uses or is a potential user of healthcare services, including their family and carers. ${ }^{1}$ While consumers are increasingly taking a more active role in their own care, this culture has not been strongly reflected in research. Researchers are often viewed as conducting research on, rather than with, consumers. ${ }^{2}$ However, it is increasingly being recognised that to successfully facilitate implementation

\section{Strengths and limitations of this study}

- Coproduction of this project with aged care consumers (clients and staff) ensured the objectives and results were relevant to their needs.

- Establishment and reinforcement of the relationships between all stakeholders throughout this process ensured the forum objectives were achieved.

- Use of a conceptual framework to guide this process strengthens this paper.

- A limitation of the stakeholder forum was the lack of a feedback survey at the end, which could have helped to inform the second stakeholder forum and other similar research.

- A larger stakeholder group could have provided a wider range of opinions and insight to the discussion topics.

of research into practice, researchers must move beyond merely providing results to actively engaging consumers throughout the research process. ${ }^{3}$ Consumer involvement benefits both consumers and healthcare researchers. For consumers, involvement in the research process increases satisfaction with their care, adherence to treatment plans and provides empowerment. ${ }^{4-6}$ From the researcher's perspective, advantages include increased participation, assistance with designing protocol and choosing relevant outcomes, and securing funding. ${ }^{7}$ Critically, consumer engagement ensures that research is relevant and therefore more likely to be considered useful by the broader community and contribute to policy changes. ${ }^{8}$

Consumer engagement requires a collaborative and active partnership between multiple stakeholders including consumers, health professionals and/or researchers at various levels of the healthcare system (eg, direct care, research and governance). ${ }^{8}$ Coproduction of research therefore represents a shift in power from researchers or decision makers to consumers. ${ }^{9}$ The 
collaboration between researchers and consumers can occur at all stages of the research process, from generating new ideas to the application of evidence into the decision-making process. ${ }^{8}$ Consumer engagement can be incorporated into research using varied methods, including stakeholder forums, focus groups, surveys and advisory panels. ${ }^{710}$ Although there are substantial ethical, practical and procedural reasons to support the coproduction of research with consumers, there is currently a lack of practical, evidence-based guidance on how best to do so. ${ }^{11}$ A lack of practical guidance may lead to tokenistic consumer involvement, rather than close collaboration with a targeted population.

\section{The Ageing Well project}

Ageing Well is a 2-year research project that aims to evaluate the implementation of social participation and quality of life (QoL) tools by aged care staff as part of routine community aged care assessments. ${ }^{12}$ The specific aims of the Ageing Well project are to: (i) ascertain the levels of social participation and QoL of community aged care clients, (2) use the findings to enhance care planning, (3) measure associations between community care services, social participation and QoL and (4) gain insight into stakeholders' perspectives of social participation and aged care issues. ${ }^{12}{ }^{13}$ In order to facilitate the implementation and uptake of the tools into the work practice of aged care staff, we sought to coproduce implementation strategies with a targeted representation of stakeholders from two metropolitan and one regional area of New South Wales, Australia.

This paper reports on one of the consumer engagement methods used in the project-stakeholder forums. The stakeholder forum required careful planning and organisation to ensure it addressed the five key principles of consumer engagement activities as outlined by the Australian Government Department of Health: purposeful, inclusive, timely, transparent and respectful. ${ }^{14}$ This framework was originally developed to facilitate better health outcomes and equity through greater consumer engagement. ${ }^{14}$ The five key principles are consistent with current consumer engagement standards and practice across public and private healthcare sectors, both in Australia and internationally. ${ }^{14}$ The well-established International Association for Public Participation Two's (IAP2's) Public Participation Spectrum outlines the different levels of participation of the consumers in engagement activities. ${ }^{15}$ The IAP2's Public Participation Spectrum demonstrates that as the consumer's role in engagement activities increases, so does the impact they have on related decisions. ${ }^{15}$ The Key Principles of Consumer Engagement framework was selected for the development of the stakeholder forums to facilitate collaboration with consumers (second highest level of engagement on the IAP2's Public Participation Spectrum), which meant their involvement and decisions would have a greater impact on the setup and content of the stakeholder forums. This framework was deemed fit-for-purpose for our stakeholder forums as it was a simple model that encouraged active consumer engagement in healthcare research and allowed us to capture the diverse opinions of both community aged care clients and staff to help shape policy, planning and service provision.

Given the lack of practical evidence in this area, researchers seeking to engage consumers in research must make judgements based on the individual circumstances of each project. ${ }^{11}$ Therefore, this paper offers insights from our experience of a coproduced research project in aged care. The aims of this paper are: (1) to describe the processes used to plan and conduct a stakeholder forum in aged care as a means of informing future uptake of consumer participatory research, including the use of a conceptual framework to guide this process and (2) to discuss how capturing and drawing on consumers' experiences of aged care can generate new research ideas and inform the delivery of more person-centred aged care services.

\section{KEY PRINCIPLES FOR CONSUMER ENGAGEMENT Purposeful: begin every engagement with a clear understanding of what we want to achieve}

The framework applied in this study enabled consumer engagement from the outset of the project, rather than merely as recipients of the research. The Ageing Well project's Working Group (research team and executive members and care coordinators from the aged care provider involved in the project) met regularly to determine the stakeholder forum's aim, content and potential participants, alongside regular discussions about project progress and resolution of any emerging issues. The group agreed that the aim of the forum was to identify and discuss the key issues involved in enabling social participation and QoL in community aged care settings. The aim would be achieved by providing an overview of the Ageing Well project and facilitating discussions about social participation. Table 1 outlines the activities, processes and outcomes of the forum. ${ }^{14}$

The first stage of coproduction focused on identifying aged care consumer priorities. In order to ensure that the aims of the stakeholder forum of both researchers and consumers were aligned, focus groups with both community aged care clients $(\mathrm{n}=21)$ and care coordinators $(n=21)$ were conducted prior to the stakeholder forum. This ensured the generation of aims that were reflective of participants' needs and concerns in aged care and further establishing the core stakeholder forum themes. This initial coproduction confirmed their relevance for all stakeholders including researchers. Themes relating to aged care staff and clients' aged care experiences were extracted from transcriptions of audio-recorded focus groups. ${ }^{16}$ Researchers met periodically throughout data collection to reach consensus on themes. The themes were then categorised into potential discussion topics for the stakeholder forum: access, effectiveness, timeliness and needs. ${ }^{16}$ 
Table 1 Outline of the ageing well stakeholder forum

\begin{tabular}{|c|c|c|}
\hline $\begin{array}{l}\text { Activity } \\
\text { (time) }\end{array}$ & $\begin{array}{l}\text { Purpose } \\
\text { (consumer engagement principle(s) } \\
\text { addressed) }\end{array}$ & Outcome \\
\hline $\begin{array}{l}\text { Morning tea } \\
(30 \mathrm{~min})\end{array}$ & $\begin{array}{l}\text { Opportunity for participants to meet. } \\
\text { (inclusive) }\end{array}$ & $\begin{array}{l}\text { Provided a supportive environment to get } \\
\text { to know each other and facilitate forum } \\
\text { discussions. }\end{array}$ \\
\hline $\begin{array}{l}\text { Welcome to the research institute } \\
\text { and overview of the forum agenda } \\
(15 \mathrm{~min})\end{array}$ & $\begin{array}{l}\text { Welcome participants and provide a clear } \\
\text { understanding of how the forum would run. } \\
\text { (purposeful, timely, transparent and } \\
\text { respectful) }\end{array}$ & $\begin{array}{l}\text { Participants understood what activities } \\
\text { would occur during the forum and how they } \\
\text { could actively engage. }\end{array}$ \\
\hline $\begin{array}{l}\text { Ice-breaker activity } \\
(15 \mathrm{~min})\end{array}$ & $\begin{array}{l}\text { Participants got to know the other members } \\
\text { in their smaller discussion groups, and } \\
\text { then feed this information back to all } \\
\text { participants. } \\
\text { (inclusive and respectful) }\end{array}$ & $\begin{array}{l}\text { Provided insight into each participant's } \\
\text { background, fostering a collaborative } \\
\text { and supportive environment for the forum } \\
\text { discussions. }\end{array}$ \\
\hline $\begin{array}{l}\text { Discussion topic } 1 \text { : access and } \\
\text { barriers to community aged care } \\
\text { services and social participation } \\
\text { activities } \\
\text { (50 min) }\end{array}$ & $\begin{array}{l}\text { Participants discussed this topic, which was } \\
\text { ranked as the most important and relevant } \\
\text { by community aged care clients and care } \\
\text { coordinators during the development of the } \\
\text { stakeholder forum. } \\
\text { (purposeful, inclusive, transparent and } \\
\text { respectful) }\end{array}$ & $\begin{array}{l}\text { Participants provided their individuals } \\
\text { opinions and experiences and came together } \\
\text { to discuss potential solutions and future } \\
\text { directions to improve access. An example } \\
\text { was issues related to transport, and current } \\
\text { and potential strategies to overcome this } \\
\text { barrier. }\end{array}$ \\
\hline $\begin{array}{l}\text { Lunch } \\
\text { (50 min) }\end{array}$ & $\begin{array}{l}\text { An opportunity for participants to refuel and } \\
\text { prevent mental fatigue. } \\
\text { During this time, a video booth was set } \\
\text { up for participants to provide feedback on } \\
\text { the Ageing Well project, the forum and/or } \\
\text { community aged care services. } \\
\text { (inclusive and respectful) }\end{array}$ & $\begin{array}{l}\text { Participants were able to stay actively } \\
\text { engaged throughout the forum and had a } \\
\text { further opportunity to network with other } \\
\text { participants. }\end{array}$ \\
\hline $\begin{array}{l}\text { Concluding remarks } \\
(15 \mathrm{~min})\end{array}$ & $\begin{array}{l}\text { The research team summarised the forum } \\
\text { activities and how the discussion topics } \\
\text { would guide future research and policies of } \\
\text { the involved aged care provider. } \\
\text { (transparent and respectful) }\end{array}$ & $\begin{array}{l}\text { Participants felt empowered and were able } \\
\text { to understand how their input would be used } \\
\text { to benefit aged care clients and services. }\end{array}$ \\
\hline
\end{tabular}

As another stage of consumer engagement of the research and to further ensure alignment of researcher and stakeholder aims for the stakeholder forum, the themes identified in the focus groups were presented to the community aged care clients and care coordinators prior to the stakeholder forum. They were then asked to rank these potential discussion topics in order of preference. The two highest ranked topics that were selected by community aged care clients and care coordinators were: (1) access and barriers to community aged care services and social participation activities and (2) the needs of community aged care clients to help them maintain social participation in their community. These became the topics of discussion of the stakeholder forum. By planning the stakeholder forum with community aged care clients and care coordinators, the research team built rapport with stakeholders and in the process were able to set the priorities for the research together. ${ }^{14}$ By meeting stakeholders during Working Group meetings and focus groups, the research team were able to discuss the aims 
of the stakeholder forum with potential participants and gauge levels of availability and interest to engage in the forum. However, doing so required investment of time and planning to include aged care consumers in this way. ${ }^{11}$ The resourcing requirements of consumer engagement must therefore be considered in their own right. ${ }^{11}$

\section{Inclusive: identify relevant stakeholders and make it easy for them to engage}

One of the challenges of coproduction of research is that engagement of stakeholders requires additional work and time to recruit willing and relevant participants, in addition to recruitment for the intervention study itself. ${ }^{11}$ The Ageing Well Working Group sought to engage a purposive sample of stakeholders and sent invitations to community aged care clients and staff (care coordinators, project officers and executive members), consumer group representatives, researchers and representatives from the Department of Health. This sample was selected to ensure the involvement of individuals that had contributed to, influenced or would be affected by the Ageing Well project. ${ }^{14}$ With the assistance of the aged care provider's care coordinators and executive members, we actively identified and targeted minority and diverse groups such as stakeholders from culturally and linguistically diverse (CALD) backgrounds, with varying levels of education; oldest-old (80 years and older); the lesbian, gay, bisexual, transgender and intersex (LGBTI) community; and regional areas. This targeted approach enabled a mixed group of participants to attend the forum $(\mathrm{n}=23)$. This included clients and staff from multiple CALD backgrounds (four Turkish, one Jewish and one Italian), six clients who did not have an education level above high school, one oldest-old client, one project officer who represented the LGBTI community and two male stakeholders.

Thoughtful seating arrangements and interpersonal skills are required to carefully manage group dynamics to enable inclusion in a mixed group. ${ }^{11}$ Stakeholder forum participants were required to work collaboratively to identify current aged care issues related to access and needs and generate solutions/preliminary models for future service use and access. To facilitate the discussions, participants were allocated to smaller groups of five to six people with representatives from each stakeholder perspective (eg, clients, staff and consumer representatives). To support the participation of the CALD community, we positioned clients who did not speak English as their main language with a staff member who spoke their predominant language to allow for maximum participation. Each group included a member of the research team to facilitate the discussions and record the group's ideas onto a shared visual reference. The groups then reconvened in a plenary session to feedback their ideas to the wider forum, which sparked further discussion among all. Participants also had the opportunity to provide feedback at a video booth about their experience and additional information about the project if they wished (stakeholder forum video available from: https://tinyurl. com/DACSStakeholder2018).

To help facilitate an inclusive environment during the stakeholder forum, a number of social activities were incorporated throughout the day, such as an icebreaker activity at the start of the forum, shared meal breaks and time to interact. These activities provided participants with the opportunity to establish and build relationships with each other so that they felt comfortable to express their opinions and thoughts. The researchers also ensured they used clear and simple English throughout the forum to help participants, in particular those from CALD backgrounds and with lower educational levels, understand the discussion topics and feel comfortable to express their opinions.

Consumer engagement in these activities also requires travel and administrative support.$^{11}$ The venue for the stakeholder forum was selected in consideration of travel distance and physical accessibility to and once at the venue. This included providing parking for a bus for those requiring physical assistance to attend. Video conferencing capabilities were also set up at the venue as an option for those in regional areas to participate. However, this was not taken up due to technological barriers identified by regional staff who reported their information technology system would not support video conferencing. This issue highlights the need for earlier and greater consideration of technological requirements in regional areas to help avoid such issues and allow for inclusion of participants regardless of location.

\section{Timely: involve stakeholders from the start and agree on when} and how to engage

Consumer engagement can be challenging for researchers as it requires the establishment and maintenance of relationships over time ${ }^{11}$ and sometimes multiple collaborations with the same organisation. The Ageing Well project arose from a previous programme of research with the same aged care provider in which staff worked together with researchers to choose the social participation and QoL tools they thought would best suit their clients. Our collaboration, built on invested time and effort, resulted in a working and harmonious relationship between researchers, the aged care provider and its clients to coproduce research. Current research supports that undergoing this process builds trust. ${ }^{17}$ Our process of engaging with the aged care provider also ensured research goals aligned with operational goals and client needs. This engagement was a key element that should be used in future consumer engagement activities as it contributed to the success of the stakeholder forum and ensured its relevance to all participants. The forum was particularly timely for the provider as it offered the opportunity for executive staff to hear feedback from clients and staff that was important and relevant in the current context of the Australian aged care sector, which is undergoing major reforms to ensure it meets current and future needs of the ageing population. ${ }^{18}$ 
At the start of the Ageing Well project, the Working Group proposed that we would conduct two stakeholder forums (halfway point and end of the project) to report on the progress of the project and to gain stakeholder feedback to guide the project and future research activities. As the focus of the stakeholder forums was on reporting the project's progress and how this would influence the project going forward, a forum was not held at the start of the Ageing Well project. Joint planning for the stakeholder forums was commenced at the very beginning of the project to ensure that there was sufficient time to organise the different aspects of the forum. Invitations to attend the stakeholder forum were sent out 3 months prior to the event to allow potential participants enough time to consider if they could attend. To help the forum run on time, participants were provided with a clear agenda and time allocations for each activity prior to the forum and again on the day. By conducting the first forum halfway through the project, participants had the unique opportunity to consider the project findings as they emerged and to reflect on how these findings related to their own experiences of social participation and community aged care services. The research team could then take the key points from the discussions and use them in a meaningful way to inform the remaining stages of the Ageing Well project and future aged care research.

\section{Transparent: all stakeholders are open and honest in their engagement and set clear expectations}

The conceptual framework used for the stakeholder forum highlights that coproduced research is as much accountable to consumers as it is to researchers. This requires conscious planning and effort on the part of researchers to promote transparency and accountability. ${ }^{11}$ Clear aims and structure were outlined prior to and during the stakeholder forum. Once the discussion topics had been decided by the community aged care clients and care coordinators, they were sent to all stakeholders. Along with this information, participants were provided with the agenda for the day, instructions on how to reach the venue and support to attend (eg, taxi voucher or parking permit) if needed. Provision of this information before the stakeholder forum meant participants would be prepared and able to engage in the forum in a meaningful way.

At the beginning of the forum, the engagement process was explained, including everyone's roles and the purpose of the forum. Once introductions and an update on the Ageing Well project was completed, the focus of the forum shifted to the discussion topics predetermined by the community aged care clients and care coordinators. Participants were provided sufficient time to generate meaningful discussions and reflect on their experiences and concerns related to the selected topics, within the smaller groups first before a plenary discussion. This approach was used to ensure participants felt comfortable to share their thoughts and opinions freely and to be open to the ideas discussed and contribute their knowledge to the topics. Topics ranged from LGBTI accessibility issues to transport needs of clients. At the conclusion of the stakeholder forum, the research team summarised the main conclusions of both discussion topics and informed participants how their opinions and ideas would be used to guide future research to promote social participation of older adults in the community.

We were provided with anecdotal positive feedback from attendees on the stakeholder forum, even when discussing barriers to social participation and service provisions. Stakeholders appeared to take this opportunity to express their opinions on the topics as well as strategies to overcome identified barriers. However, in future workshops we would conduct a satisfaction survey at the end of the session for participants to record their feedback and provide any potential areas of improvement in a more rigorous manner. This process will be incorporated into the second stakeholder forum at the end of the Ageing Well project to help guide future research and ensure it is relevant to all stakeholders.

\section{Respectful: acknowledge and respect the expertise, perspective and needs of stakeholders}

Engaging consumers in the coproduction of research requires professional etiquette and courtesy to ensure a positive experience of participating in research. ${ }^{11}$ Throughout the preparation and progress of the stakeholder forum, the research team encouraged the inclusion of all perspectives to foster an environment of mutual respect and collective inquiry in the discussion topics. This was achieved by allowing each participant to have their views heard and contributions acknowledged, both verbally in discussions and by transparently recording (written and audio) the input of participants as valued and important information. To facilitate understanding and discussion, the research team ensured that the information communicated was presented in language accessible by all. The expertise and perspectives of the participants was further acknowledged through their involvement in the writing of this publication. When conducting consumer engagement activities with a mixed group of stakeholders, there is always the potential challenge of managing different views and opinions that can occur between stakeholder groups. However, this was not an issue in the stakeholder forum as all participants openly discussed their views and listened to each other without any negative or disrespectful comments.

\section{DISCUSSION}

Consumer engagement in research brings together service users, healthcare professionals and other key stakeholders with a vested interest in a particular issue to develop, implement and evaluate health services. Our stakeholder forum successfully brought together multiple stakeholders to work collaboratively to inform the aged care service planning process and to facilitate quality 
improvement changes in practice. For the Ageing Well project, close involvement of aged care staff and clients allowed for evaluation of an iteratively coproduced model, and feedback received at the initial stakeholder forum will be used to guide the final forum. We as the researchers were able to further develop our relationship with the aged care provider and their clients, facilitating buy-in to the next phase of the research, as well as test some of our ideas for future grants. Clients and aged care provider staff involved in the stakeholder forum were able to share their experiences with people they would not normally have the opportunity to do so with (eg, Department of Health representatives, the aged care provider's executive members and clients that lived in different areas) and also gained a better understanding of the research and how their contributions had influenced the Ageing Well project. The Department of Health representatives reporting gaining a greater understanding of the Ageing Well project than what was possible from review of the grant application alone. Their attendance of the stakeholder forum further influenced them to consider how they could change the grant application process to gain a better insight into future projects.

Unlike similar processes that only involve consumer representatives, we targeted involvement of community aged care clients, including minority and diverse groups, during the planning stage and at the forum. This required thoughtful planning and preparation in line with the consumer engagement framework adopted for the stakeholder forum to foster colearning, networking and a positive sense of ownership of aged care services among stakeholders and generate innovative ideas from the grassroots of aged care. This was demonstrated through the positive experiences of the forum that participants shared with each other and the research team during the discussion topic feedback sessions, shared meal breaks and at the video booth. Clients expressed their willingness to be involved in the Ageing Well project and appreciated the time taken to consider their perspectives on the type of activities that can support older adults living in the community. Community aged care clients and care coordinators reflected that the discussion topics were relevant for themselves and the wider population of older people living the community.

At the conclusion of the forum, stakeholders were invited to leave their details so they could be involved in future healthcare research projects. One indicator of success of this forum was that all stakeholders expressed interest in continuing their involvement in the Ageing Well project and other research activities. Four weeks after the forum was completed, all stakeholders were provided with a newsletter that summarised the aims and outcomes of the forum, along with a certificate of appreciation and photos from the forum. To further enhance the quality of future forums, it would be beneficial to have stakeholders complete a feedback questionnaire at the end of the forum. This would ensure that the feedback is accurately captured and enhance the research team's ability to develop tailored and meaningful consumer engagement activities. Future forums, depending on their focus, should consider other factors that may drive further success. For instance, larger stakeholder forums may consider the logistics regarding stakeholder's transport options, broader consumer representatives as well as additional representatives and timing. For forums that wish to generate future research directions, alternative activities that promote discussion, such as rating cards, could be used.

Ultimately, this forum enabled stakeholders (policy makers, clients and care coordinators) who rarely meet in one place to reflect on their aged care experiences, to: (1) work together to identify relevant needs and priorities for improvement of aged care services; and (2) devise strategies to address these needs. This process facilitated an understanding of consumers' needs and existing gaps in aged care services and the circumstances that can impact the delivery and implementation of services. This type of consumer engagement activity is critical to ensure aged care research is tailored to the needs of consumers. Doing so supports consumer-centred aged care services that empower consumers to engage in decision making about both their own care and the care needs of the wider community.

Future research should use the topics, stories and feedback obtained from stakeholders during forums to inform and reflect on how consumer engagement can improve research outcomes. The primary facilitator of consumer engagement in our research lay in our investment in a strong foundation of trust with the aged care provider. This included multiple working group meetings, examining deficiencies and aligning with the provider's aims. Ultimately, by working collaboratively over a long period of time, encompassing multiple research opportunities (psychosocial tool selection and software implementation), ${ }^{19} 20$ a successful forum was made possible.

The direct benefit of consumer engagement to research is not always able to be quantified. ${ }^{11}$ Coproduction of this research with aged care consumers required significant investment of time and resources and required skill, respect and courtesy to build trust and engagement with stakeholders. The benefits of this process are demonstrated through the establishment and reinforcement of relationships between the different stakeholders, the codevelopment of new research ideas through the stakeholder discussions and the ongoing interest and involvement of the different stakeholders in the Ageing Well project.

Twitter Mikaela Jorgensen @mikaelajorgensn and Andrew Georgiou @ AGeorgiouMQ

Acknowledgements The authors would like to acknowledge all stakeholders that participated and provided valuable contributions to the forum.

Contributors LB was the major contributor to the conception, drafting and revision of the manuscript. $A G, M J, J S$ and JW received funding for the Ageing Well project. JS, AN, MJ and MM made substantial contributions to the conception, drafting and revision of the manuscript. JW and AG made substantial contributions to the drafting and revision of the manuscript. WL, EG and FH made substantial 
contributions to the review and revisions of the manuscript. All authors read and approved the final manuscript and are in agreement to be accountable for all aspects of the work in ensuring that questions related to the accuracy or integrity of any part of the work are appropriately investigated and resolved.

Funding This work was supported by the Australian Government Department of Health Dementia and Aged Care Services Fund (Agreement ID: 4-4Z09T5A, Schedule ID: 4-4Z09T62).

Competing interests None declared.

Patient consent for publication Not required.

Ethics approval Ethical approval was granted by the Macquarie University Human Research Ethics Committee (reference number: 5201700912). Participants provided written consent for their involvement in the stakeholder forum. They also provided written consent for photos and videos from the forum to be used for promotional and publication purposes.

Provenance and peer review Not commissioned; externally peer reviewed.

Open access This is an open access article distributed in accordance with the Creative Commons Attribution Non Commercial (CC BY-NC 4.0) license, which permits others to distribute, remix, adapt, build upon this work non-commercially, and license their derivative works on different terms, provided the original work is properly cited, appropriate credit is given, any changes made indicated, and the use is non-commercial. See: http://creativecommons.org/licenses/by-nc/4.0/.

\section{REFERENCES}

1 Queensland Health. Queensland health position statement: consumers and community participation: to promote community engagement in health. Brisbane: Queensland Health, 2003.

2 Thornton S. Beyond rhetoric: we need a strategy for patient involvement in the health service. BMJ 2014;348.

3 Krzyzanowska MK, Kaplan R, Sullivan R. How may clinical research improve healthcare outcomes? Ann Oncol 2011;22:vii10-15.

4 Jo Delaney L. Patient-Centred care as an approach to improving health care in Australia. Collegian 2018;25:119-23.

5 Ruco A, Nichol K. Patient engagement in research and innovation: a new framework. J Med Imaging and Sci 2016;47:290-3.

6 Minogue V, Girdlestone J. Building capacity for service user and carer involvement in research: the implications and impact of best research for best health. Int J Health Care Qual Assur 2010;23:422-35.
7 Domecq JP, Prutsky G, Elraiyah T, et al. Patient engagement in research: a systematic review. BMC Health Serv Res 2014;14:89.

8 Carman KL, Workman TA. Engaging patients and consumers in research evidence: applying the conceptual model of patient and family engagement. Patient Educ Couns 2017;100:25-9.

9 Flinders M, Wood M, Cunningham M. The politics of co-production: risks, limits and pollution. evid policy 2016;12:261-79.

10 Guise J-M, O'Haire C, McPheeters M, et al. A practice-based tool for engaging stakeholders in future research: a synthesis of current practices. J Clin Epidemiol 2013;66:666-74.

11 Oliver K, Kothari A, Mays N. The dark side of coproduction: do the costs outweigh the benefits for health research?. Health Res Policy Sys 2019;17.

12 Brett L, Georgiou A, Jorgensen M, et al. Ageing well: evaluation of social participation and quality of life tools to enhance community aged care (study protocol). BMC Geriatr 2019;19:78.

13 Australian Institute of Health Innovation. Ageing well - a social participation and engagement tool, 2017. Available: https://www. mq.edu.au/research/research-centres-groups-and-facilities/ healthy-people/centres/australian-institute-of-health-innovation/ news-and-events/news/news/ageing-well-a-social-participation-andengagement-tool; [Accessed 13 Dec 2018].

14 Australian Government Department of Health. Health Stakeholder engagement framework. in: health do, editor. 2017. Canberra: Commonwealth of Australia, 2018.

15 International Association for Public Participation. lap2's public participation spectrum, 2014. Available: https://www.iap2.org au/Tenant/C0000004/00000001/files/IAP2_Public_Participation_ Spectrum.pdf; [Accessed 06 Dec 2018].

16 Guest G, MacQueen KM, Namey EE. Applied thematic analysis. thousand oaks, California, 2012. Available: http://methods.sagepub. com/book/applied-thematic-analysis

17 Boaz A, Hanney S, Borst R, et al. How to engage stakeholders in research: design principles to support improvement (report, 2018

18 Australian Government Department of Health. Aged care reform, 2019. Available: https://agedcare.health.gov.au/aged-care-reform; [Accessed 28 Jul 2019].

19 Siette J, Georgiou A, Jorgensen M, et al. Integrating social engagement instruments into Australian community aged care assessments to enhance service provision. Health Soc Care Community 2018;26:810-8.

20 Douglas HE, Georgiou A, Tariq A, et al. Implementing information and communication technology to support community aged care service integration: lessons from an Australian aged care provider. Int $J$ Integr Care 2017;17. 